Connotas. Revista de crítica y teoría literarias 


\begin{tabular}{|ll|}
\hline PQ6001 & Connotas. Revista de crítica y teoría literarias / \\
Director Fortino Corral Rodríguez.-Hermosillo, Sonora: \\
unIson. Departamento de Letras y Lingüística. \\
C2011. \\
V-: $23 \mathrm{~cm}$. \\
Semianual \\
Año VII, No. $12(2011)$ \\
ISSN: 1870-6630 \\
Incluye bibliografía. \\
1. Literatura española - Historia y crítica-Publicaciones \\
periódicas. 2. Literatura hispanoamericana - Publicaciones \\
periódicas. I. Corral Rodríguez, Fortino, dir.
\end{tabular}

CONNOTAS. REVISTA DE CRÍTICA Y TEORÍA LITERARIAS. Año VII, núm. 12, enero junio 2011, es una publicación semestral editada por la Universidad de Sonora, a través de la División de Humanidades y Bellas Artes, en el Departamento de Letras y Lingüística. Blvd. Luis Encinas y Blvd. Rosales s/n, Col. Centro, C.P. 83000, Hermosillo Sonora; Tel. (662) 2592 136, (662) 2592 157, <www.uson.mx>, <http://www.connotas.uson.mx, connotas@capomo.uson.mx>. Editor responsable: Rosario Fortino Corral Rodríguez. Reservas de Derechos al Uso Exclusivo núm. 04-2006-020714184900-102. ISSN: 1870 6630; ambos otorgados por el Instituto Nacional del Derecho de Autor. Licitud de Título núm. 13434 y de Contenido núm. 11007, otorgados por la Comisión Calificadora de Publicaciones y Revistas Ilustradas de la Secretaría de Gobernación. Impresa en Impresos RM S.A. de C.V., Privada Miguel Alemán no. 17, col. San Benito, Hermosillo, Sonora, México. Tel. 2 100212, e-mail impresosrm@gmail.com. Este número se terminó de imprimir el 5 de octubre de 2011 con un tiraje de 300 ejemplares. Las opiniones expresadas por los autores no necesariamente reflejan la postura del editor de la publicación.

Se autoriza la reproducción total o parcial de los contenidos de la presente publicación, siempre y cuando se acredite adecuadamente el origen de los mismos.

Este número se publicó con apoyo del Programa Integral de Fortalecimiento Institucional

Datos de contacto para la publicación: División de Humanidades y Bellas Artes, Departamento de Letras y Lingüística; Apartado Postal 793, Col. Centro, C.P. 83000, Hermosillo, Sonora, México. Tels.: (662) 259-21-87, Tel-fax 212-55-29. Correo electrónico: connotas@capomo.uson.mx Página web: http://www.connotas.uson.mx 


\section{Connotas. Revista de crítica y teoría literarias}

Año VII / Núm. 12 / Enero-junio 2011

COMPILAdOR DE ESTE NÚMERO

César Avilés Icedo

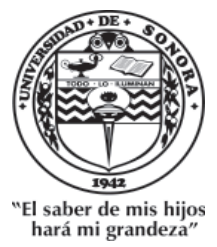

UNIVERSIDAD DE SONORA 


\section{UNIVERSIDAD DE SONORA}

RECTOR

Heriberto Grijalva Monteverde

VicerReCTORA

Arminda Guadalupe García de León Peñúñuri

Secretario General Académico

Enrique Fernando Velázquez Contreras

División de Humanidades y Bellas Artes

María Rita Plancarte Martínez

DePARTAMENTO DE LETRAS Y LINGÜÍSTICA

Martha Martínez Figueroa

COMItÉ EDITORIAL INTERNO

César Avilés Icedo

Rosa María Burrola Encinas

Fortino Corral Rodríguez

Leticia Martínez Figueroa

Jesús Abad Navarro Gálvez

Gabriel Osuna Osuna

María Rita Plancarte Martínez

DiRECTOR

Fortino Corral Rodríguez

Giuseppe Bellini

Universidad de Milán

Luis Beltrán Almería

Universidad de Zaragoza

Helena Beristáin

Universidad Nacional Autónoma de México

Raúl Bueno-Chávez

Dartmouth College

Evodio Escalante

Universidad Autónoma Metropolitana

Beatriz González-Stephan

Rice University

Aníbal González Pérez

Yale University

Aurelio González Pérez

El Colegio de México

Yvette Jiménez de Báez

El Colegio de México

Nelson Osorio Tejeda

Universidad de Santiago de Chile

\section{CONSEJO INTERNACIONAL}

Carlos Pacheco

Universidad Simón Bolivar

Rafael Olea Franco

El Colegio de México

Joan Oleza Simó

Universidad de Valencia

Julio Ortega

Brown University

Luz Aurora Pimentel

Universidad Nacional Autónoma de México

Susana Reisz

The City University of New York

José Carlos Rovira

Universidad de Alicante

Charles Tatum

The University of Arizona

Jorge Urrutia

Universidad Carlos III de Madrid

Emil Volek

Arizona State University 


\section{Índice}

\section{Artículos}

La ciudad fronteriza de Luis Humberto Crosthwaite en Estrella de la calle sexta e Instrucciones para cruzar la frontera

Martín Torres SAUChetT . . . . . . . . . . . . . 9

Artífices y simuladores: el influjo de los medios masivos y la cultura popular en la literatura latinoamericana del siglo XX Amalia Franco Castaño . . . . . . . . . . . . . . . . . 27

“Teoría del túnel”: El pre-texto de Rayuela Margarita Díaz de León Ibarra . . . . . . . . . . . . . . 45

Metaficción hispanoamericana y crisis de la representación literaria del sujeto

Jesús Eduardo Oliva Abarca . . . . . . . . . . . . 61

Los refranes y los poemínimos: análisis de una relación intertextual

IsAbelle Pouzet . . . . . . . . . . . . . . . . . . . . . . . . 79

\section{Notas}

La ciudad como categoría estética e ideológica en Cartas de relación de Hernán Cortés y Grandeza mexicana de Bernardo de Balbuena Jesús Abad Navarro Gálvez . . . . . . . . . . . . . . . . . 99 
Hacia una hermenéutica estridentista: de la crítica romántica a la crítica de vanguardia

Alberto Rodríguez González . . . . . . . . . . . . . . . . 111

Casas de encantamiento y El espía del aire, de Ignacio Solares: la reflexión de la escritura

Alejandra Sánchez Aguilar . . . . . . . . . . . . . . . . . . 123

\section{Reseñas}

Gilberto Giménez. Estudios sobre la cultura y las identidades sociales. México: Conaculta/ITESO, 2007

Ana Lourdes Álvarez Romero . . . . . . . . . . . . . . . . . . . 135

Angélica Tornero. El mal en la narrativa de Inés Arredondo. México: Casa Juan Pablos/Universidad Autónoma del Estado de Morelos, 2008

Griselda Córdova Romero . . . . . . . . . . . . . . . . . . . . . . . 141

Guadalupe Fernández Ariza, coord. Literatura hispanoamericana del siglo XX. Historia y maravilla. España: Universidad de Málaga, 2006

Mayra Alejandra Borbón Espinoza . . . . . . . . . . . . . . 147

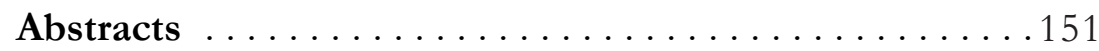

Résumés ... . . . . . . . . . . . . . . . . . . . . 157

Normas editoriales ..................... 163 
Connotas. Revista de Crítica y teoría literarias/AÑo VII, Núm. 12/2011

\title{
Hacia una hermenéutica estridentista: de la crítica romántica a la crítica de vanguardia
}

\author{
Alberto Rodríguez GonzÁlez ${ }^{*}$
}

\section{Resumen:}

Evodio Escalante propone que la vanguardia estridentista ha padecido de una "hermenéutica de la exclusión," de la cual todavía no se ha repuesto. Quien se interese por estudiar el estridentismo, dice, deberá arreglárselas por sí mismo sin contar con el respaldo de la fuerza autovalidadora que genera una tradición. La propuesta del presente trabajo es que la construcción de una hermenéutica debe partir desde el interior mismo del universo vanguardista para abrir la comprensión de la obra estridentista.

Palabras clave:

Estridentismo, crítica literaria, tradición, Romanticismo, Clasicismo.

Para ver una cosa hay que comprenderla. ... Si viéramos realmente el universo, tal vez no lo entenderíamos.

Jorge LUIS BORges

Germán List escribía en 1923 los versos "Mutt y Jeff no sabían/ que ella se extravió en mis brazos/por esto la Academia/no la puso en su diccionario," con los cuales, a tono con la carcajada estridentista cuya efímera sonoridad comenzaba en ese momento,

* Universidad Autónoma Metropolitana. 
buscaba mofarse de la Academia al ponerla al mismo nivel de una tira cómica. Sus versos, aunque hablan en pasado, tendrían a la postre una carga profética contra la propia obra estridentista, pues acabarían como esa "ella:" fuera de los diccionarios de la Academia.

Evodio Escalante identifica en esta clase de versos uno de los factores que habrían creado una "hermenéutica de la exclusión" contra la misma vanguardia estridentista, de la cual ésta aún no se ha repuesto. Señala, sin embargo, la necesidad de que la crítica literaria mexicana desarrolle un "espacio de comprensión" desde el cual se valore el papel del movimiento estridentista en la construcción de la cultura mexicana contemporánea (39).

Luego de estudiar el discurso descalificador contra el estridentismo, Escalante advierte que el crítico interesado en estudiarlo deberá "arreglárselas por sí mismo sin contar con el respaldo de la fuerza autovalidadora que genera una tradición” (24). Surge entonces, como tarea pendiente, la construcción de ese espacio de comprensión donde el estridentismo encuentra su justa dimensión. Contribuir a la apertura de ese espacio es el propósito de este trabajo.

El primer problema es plantear desde qué plataforma teórica podría desarrollarse una herramienta adecuada para este fin. La pregunta es: ¿cómo superar la hermenéutica de la exclusión y alcanzar una hermenéutica de la apertura? Si, como señala Escalante, los estridentistas habrían contribuido a dar el portazo que a la postre los dejaría fuera de la tradición, y si el espacio de comprensión ha estado cerrado desde entonces a la obra estridentista, la tarea pendiente es, por tanto, abrir dicho espacio comprensivo. Aplicando la máxima homeopática similia similibus curantur, podemos aventurar la hipótesis de que la apertura del espacio de comprensión debe provenir de la misma cerrazón de la cual hacía apología el grupo estridentista.

En este contexto, mi propuesta es que la construcción de una hermenéutica para abrir la comprensión de la obra estridentista debe partir desde el interior mismo del universo vanguardista; es decir, para hacer la crítica de la vanguardia, ésta ha de surgir de la obra vanguardista misma, de forma análoga como ya señalaba tempra- 
namente el romanticismo alemán, con referencia a la interpretación de obras de aquel periodo.

Cuando Escalante estudia la manera en que una buena parte de la crítica mexicana ha descalificado reiteradamente el movimiento estridentista, toma como ejemplo paradigmático el caso de Vicente Quirate, para quien el estridentismo "no habría pasado la prueba de fuego de la página impresa" y su valor estaría más "en las acciones que en la obra" (185). Al respecto, Escalante concluye que el juicio adverso de Quirarte se construye desde la tradición elegida por el crítico y desde la cual habla. Esta tradición, explica, le proporciona a Quirarte hábitos de lectura determinados, así como los patrones desde donde se valora cuál es un buen poema y cuál no lo es. Así, al no reproducir dichos parámetros, la obra estridentista es calificada negativamente (23). Acerca de la visión distorsionada de la obra de vanguardia ofrecida por dichos criterios valorativos, Silvia Pappe explica en su tesis doctoral El movimiento estridentista atrapado en los andamios de la historia que la rebelión estridentista contra la tradición llevaría en sí misma su condena, pues para desgracia de los jóvenes vanguardistas, aquella tradición que buscaban sepultar sobrevivió, y con tan buena salud como para seguir imponiéndose como institución rectora sobre ellos.

En estos criterios valorativos aplicados en detrimento de la obra estridentista, opera lo que el propio Quirarte reconoce-quizá como un soslayado mea culpa- "nuestra tendencia a glorificar actitudes clasicistas de nuestros hombres de letras" (186). Esta frase es de cierta manera la adscripción de Quirarte a esa tradición que hace de la crítica literaria más un ejercicio de valoración que de comprensión, ubicándose, desde la perspectiva de Walter Banjamin, en una corriente de pensamiento que habría sido superada por el romanticismo alemán.

Cuando Walter Benjamin estudia el concepto de crítica en el Romanticismo alemán, considera como aporte fundamental de éste precisamente el hecho de que el romanticismo supera los criterios valorativos impuestos por el clasicismo y difundidos por ciertos historiadores del arte para quienes éste debía analizarse metódicamente a partir de conceptos como la mesura y serenidad, cualida- 
des encarnadas idealmente por el arte grecorromano. Benjamin señala: "Sólo con los románticos se impuso definitivamente la expresión crítico de arte, frente a la más antigua, juez de arte. Con ello se evitaba la representación de un abrir juicio sobre obras de arte, de una sentencia dictada sobre leyes escritas o no escritas..." (53). La caracterización que hace Benjamin del concepto de crítica del Romanticismo es especialmente útil al momento de buscar herramientas para construir un modelo de análisis de la obra estridentista que vaya más allá de los criterios clasicista. Destaca que la crítica romántica no es una estructura metódica cuya finalidad sea el enjuciamiento de una obra, sino que busca una "última determinación de sentido" ajena a cualquier fin informativo o pedagógico. Para los románticos, la crítica guarda con la obra una relación de identidad, a tal grado que ésta es "consumada" por aquélla; en síntesis, para Benjamin, la crítica romántica es "más bien un producto que en su origen es ciertamente ocasionado por la obra, pero en cuya existencia es independiente respecto a ésta y, como tal, por principio, no puede diferenciarse de ésta" (107).

El concepto de crítica de arte de los románticos está unido indisolublemente, explica Benjamin, al "credo metafísico" que ellos profesaban a la idea del arte como un medio de reflexión, el cual permite el conocimiento de su propia idea y de sus productos (63). La concepción del arte como un movimiento que contiene en sí mismo su propio conocimiento se funda en la teoría del conocimiento de la Naturaleza desarrollada por los románticos a partir del concepto de reflexión. Para Friedrich Schlegel y Novalis, apunta Benjamin, los objetos susceptibles de ser conocidos, como todo lo real, se encuentran dentro del absoluto de la reflexión, a la cual definen como el pensar del pensar. Este paradigma de la reflexión como un pensar que al pensar se conoce a sí mismo incluye en consecuencia a todo el conocimiento en general. Dado que este pensar del pensar existe para los románticos axiomáticamente a priori como un conocimiento del pensar en cuanto el pensar originario, es decir como el sentido, su postura tiene implicaciones ontológicas.

A este respecto, explica Benjamin: 
En razón de este axioma, el medio de la reflexión se convierte en sistema, el absoluto metódico en ontológico. Éste puede pensarse como determinado de múltiples maneras: como naturaleza, como arte, como religión. etc., pero nunca perderá el carácter de medio de pensamiento, de nexo de una relación pensante. Por consiguiente, en todas sus determinaciones el absoluto sigue siendo algo pensante, y una esencia pensante es todo lo que llena. Con ello queda dado el principio romántico de la teoría del conocimiento de los objetos. Todo lo real, todo lo que está en el absoluto piensa; y puesto que este pensar es la reflexión, sólo puede pensarse a sí mismo. (55)

A partir de este modelo, para los románticos la obra de arte, en cuanto parte de lo real, posee su propio pensar que es un pensar sobre sí misma. Sin embargo, esta esencia pensante no requiere de poseer un yo para pensarse a sí misma, pero la esencia pensante que es la obra de arte requiere, para consumarse como reflexión, de la crítica, pues a través de ella la obra se manifiesta como su propio autoconocimiento. Este conocimiento como autoconocimiento encuentra ciertas restricciones cuando Novalis considera que lo similar sólo puede conocer lo similar; así, el ojo sólo puede ver al ojo, la imaginación a la imaginación y sólo un dios a otro dios, lo cual deriva, siguiendo a Benjamin, en la premisa de que las cosas pueden sólo conocerse a sí mismas, pero además admiten ser conocidas exclusivamente por aquello que les es similar (57). De ahí entonces que la obra comparte con su crítica una relación de identidad, pues es en la crítica donde la obra encuentra su autoconocimiento. Pero para que este proceso de conocimiento se dé plenamente, es condición necesaria que la crítica sea similar a la obra. Y es precisamente esta restricción epistemológica la que considero fundamental para construir la crítica de la obra estridentista, de tal suerte que a través de su discurso incendiario y en ocasiones sectario los textos estridentistas estarían simplemente clamando por las lecturas específicas para consumarse y reclamando ese ojo, esa imaginación 
cómplice, que sólo al comprenderlos pudiera sacarlos de la invisibilidad.

Más allá de que el tono desafiante de los textos estridentistas, ya sean manifiestos, poemas, relatos o sus hibridaciones, estaría en consonancia con el arrebato inherente a la vanguardia, esta exaltación de su propia singularidad es la manifestación de la conciencia de que su propia naturaleza innovadora los erigiría como un producto difícil de asimilar por el lector de su época, tanto que la estética estridentista se planteaba a sí misma como un problema. Así lo expresa Germán List cuando desde Puebla se adhiere al movimiento por considerarlo la necesaria nueva vía para el arte y declara: "Cuando languidecen las canciones sobre el tema absurdo de una tristeza 'pose' se hacía necesario que una mano borrara la vieja ecuación de las estrellas, para plantear un problema de vida nueva y ansia en traje de diario" ("Switch" 237).

El estridentismo, pues, se ofrece como un problema, pero el término, más que sólo quedarse en la acepción de algo que causa dificultades, implica el disgusto que deliberadamente quería provocar. Además, en consonancia con las tesis románticas de la obra de arte, en esta declaración está vibrando el sentido matemático del termino "problema," en el que una incógnita ha de despejarse a partir de los elementos dados, es decir, la solución al problema que es el texto estridentista está dada dentro de la obra misma como una manifestación de su propia autoconciencia pero a la espera de la conciencia capaz de resolverlo. Esta lectura se apoya en la palabra ecuación, la cual, si bien remite al campo semántico de la ciencia y con ella al campo del conocimiento sistemático, es usada en un sentido más bien irónico, pues, como ya postulaban los románticos (y, como veremos más adelante, también para los estridentistas), el conocimiento de la obra de arte no es un ejercicio metódico.

Así, puede vislumbrarse que para el estridentismo la recepción de la obra de arte no es pasividad, sino que, a tono con el dinamismo que pregonan, los escritores agrupados en este movimiento buscan que el lector/receptor participe de la experiencia creadora del vanguardismo y se involucre con la obra en el círculo reflexivo postulado por los románticos. Por ejemplo, en la revista Irradiador 
de 1923, aparece sin firma una "carta abierta" dirigida al "MéxicoEstándar" que, bajo el título "A LA NARíz DEL GUARDA-AVENIDA QUE APRENDE POR EXCESO DE VELOCIDAD,” dice:

Se ha visto que se lee para divertirse. Para deleitarse. Para ilustrarse. Para dormirse. Pero por aventura no. (8)

En este pasaje se plantea la necesidad de eliminar la pasividad del acto de leer y hacer de ello una aventura, o, con otras palabras, un problema: leer debería convertirse en el ánimo de despejar incógnitas. Por otro lado, en las primeras líneas de la carta se deplora la tibieza de "las medias tintas," ante las cuales el texto prefiere los "auditorios congelados;" de esto se infiere la lógica de que, ante una mala recepción, es mejor una no-recepción: ante la incomprensión es mejor el hermetismo:

Así-sin duda- encontré mi fórmula para REIR-SIN-MOTIVO. Como también inventivas que para salir de mi megáfono sin resultar sobrenatural necesitan otra temperatura.

Otra sin estupores meridionales. Prefiero auditorios congelados.

Son nuevas mis páginas.

Si bien aquí se manifiesta de nuevo la altanería estridentista, me parece que si se toma como referencia la idea de que la obra estridentista busca desde sí misma su propia lectura, es posible percibir en esa voz desafiante el malestar ante las mínimas expectativas de encontrar esa lectura ideal en medio de un entorno cultural que se mostraba adverso a la voz vanguardista. Tal panorama cultural, considerado por la vanguardia como anquilosado, aparece en el discurso estridentista como la encarnación de una enfermedad, de un mal que obnubila el entendimiento y la mirada, sobre todo de aquellos jóvenes en quienes el estridentismo esperaba detonar. Por ello, ya en el primer manifiesto, Maples Arce postulaba al estri- 
dentismo como una acción de carácter "higienista" ante la infección padecida por la sensibilidad artística:

¡Chopin a la silla eléctrica! He aquí una afirmación higienista y detersoria..

¡Chopin a la silla eléctrica! (M. M. A. trade mark) es una preparación maravillosa; en veinte y cuatro horas exterminó todos los gérmenes de la literatura putrefacta y su uso es agradibilísimo y benéfico. (Schneider, El estridentismo o una literatura de la estrategia 269-270)

En otro ejemplo, para el Manifiesto número 2, ya firmado junto con Gemán List, los estridentistas lanzan el llamado a los jóvenes "no contaminados." Ante la plaga que azota al arte, el estridentismo toma en sus manos la acción terapéutica. Por tal razón, List declara lo siguiente al hacer el recuento del movimiento: “... era necesario curar por la fatiga a los histéricos, posesos de todos los miedos de la vida al viento de la gasolina que consolaban sus livideces puerperales, meciéndose en la cuna del presupuesto..." (El movimiento 50). Una vez diagnosticada la enfermedad, la cura resulta evidente: el estridentismo mismo, o mejor aún, "estridentina," un destilado de su esencia más pura, tal como se lee en la página tres del número 1 de Irradiador: "Estridentina = Específico infalible contra la pesadez cerebral infecciosa y la miopía intelectual aguda".

Si la mirada comprensora está "miope" a causa de la "pesadez cerebral," el estridentismo sería pues invisible; sin embargo, paradójicamente se concibe a sí mismo como el remedio capaz de otorgar la lucidez a la conciencia colectiva, pues, como ya señalaba Benjamin sobre el esquema de la hermenéutica romántica, en la relación pensante del conocer, el lector de la obra, al conocerla, se conoce a sí mismo gracias al movimiento de la reflexión absoluta.

En este punto podría objetarse que identificar los conceptos románticos con la escritura estridentista puede resultar un anacronismo. En respuesta, basta recordar el comentario de Octavio Paz ante la descalificación lanzada por los Contemporáneos contra la 
poesía de Manuel Maples Arce a causa de sus "deplorables regresiones románticas" (Cuesta 157), cuestionamiento que el nobel mexicano califica como una acusación "miope," pues considera que el espíritu romántico sería precisamente el impulsor de toda tendencia renovadora en el arte (Poesía en movimiento 17). En este contexto, no es casual la consonancia entre el concepto de crítica del romanticismo y la manera en que los estridentistas consideraban que debían ser leídos sus textos.

\section{Conclusiones}

Cuando Luis Mario Schneider comenta la recepción de Andamios interiores, primer libro de Manuel Maples Arce, dice que la única crítica que logra captar en profundidad las innovaciones estéticas es la de Arqueles Vela, quien afirmaba: "para comprender las tendencias nuevas hay que disgregarse. Para comprender a Maples Arce hay que disgregarse. Hay que distender todas las ligaduras sensitivas. Hay que arrancarse el cerebro y lanzarlo al espacio" (cit. en Schneider, El estridentismo o una literatura de la estrategia 56). La nota fue considerada por Maples Arce como una adhesión a sus ideas estéticas e invita al periodista a sumarse a las filas del estridentismo. Tanto Evodio Escalante como Vicente Quirarte ya han recalcado la necesidad de estudiar al estridentismo dejando atrás tanto la adhesión incondicional o la descalificación a priori. A la luz de las tesis de Benjamin sobre el concepto de crítica romántica, como aquella que surge de la obra misma como su consumación, la crítica vanguardista de Vela permite ratificar que la crítica de la obra estridentista debe construirse desde el andamiaje conceptual sobre el cual ella misma se eleva y se muestra desafiante. Para abrir el espacio de comprensión del estridentismo, el primer paso será entonces distender las ligaduras críticas y, una vez comprendido aquél, poder al fin verlo plenamente. 


\section{Bibliografía}

"A la naríz del guarda-avenida que aprende por exceso de velocidad," Irradiador. Revista de vanguardia. No. 1 (1923): 8-9. <http:/ /hdl.handle.net/10524/1004; http:/ / evols.library.manoa. hawaii.edu/handle/10524/1004>

Benjamin, Walter. El concepto de critica de arte en el Romanticismo alemán. Vol. I, libro I. Madrid: Abada Editores, 2005.

Cuesta, Jorge. Antología de la poesía mexicana moderna [1928]. México: Secretaría de Educación Pública/Fondo de Cultura Económica, 1985.

Escalante, Evodio. Elevación y caída del Estridentismo. México: Consejo Nacional para la Cultura y las Artes/Ediciones sin Nombre, 2002.

List Arzubide, Germán. Poemas estridentistas. México: Ediciones El Tucán de Virginia, 1998.

—_. El movimiento estridentista [1926]. México: Secretaría de Educación Pública, 1987.

- "Switch" [1923], Manifiestos, proclamas y polémicas de la vanguardia literaria hispanoamericana. Ed. Nelson Osorio. Biblioteca Ayacucho, 132. Caracas: Ayacucho, 1988.

Quirarte, Vicente. "La doble leyenda del Estridentismo." Bibliografía y antología crítica de las vanguardias literarias. Tomo 4. Merlin $\mathrm{H}$. Forster (Ed.). México: Iberoamericana/Veuvert, 2001. 185-193. [Artículo aparecido originalmente en 1993]

Paz, Octavio. Poesía en movimiento. México 1915-1966. México: Siglo XXI, 1966.

- Lo bijos del limo, del romanticismo a la vanguardia. México: Seix Barral, 1989.

Pappe, Silvia. "El movimiento estridentista atrapado en los andamios de la historia." Tesis doctoral. Universidad Nacional Autónoma de México, 1998.

Schneider, Luis Mario. El estridentismo o una literatura de la estrategia. México: Consejo Nacional para la Cultura y las Artes, 1997. 
- El estridentismo. La vanguardia literaria en México. México: Universidad Nacional Autónoma de México, 2007.

- El estridentismo, un gesto irreversible. México: Consejo Nacional para la Cultura y las Artes/Instituto Nacional de Bellas Artes, 1998. 